\title{
Quantitative LC-MS/MS analysis of seven ginsenosides and three aconitum alkaloids in Shen-Fu decoction
}

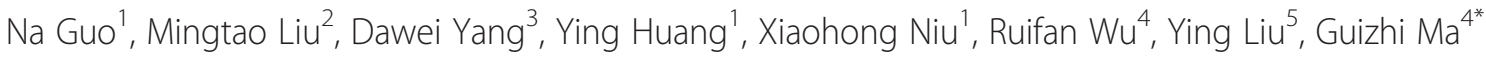 \\ and Deqiang Dou ${ }^{6^{*}}$
}

\begin{abstract}
Background: Shen-Fu decoction is a traditional Chinese medicine prescription with a 3:2 ratio of Radix Ginseng and Fuzi (Radix Aconiti lateralis praeparata). Ginsenosides and alkaloids are considered to be the main active components of Shen-Fu decoction. However, no analytical methods have been used to quantitatively analyse both components in Shen-Fu decoction simultaneously.

Results: We successfully developed a rapid resolution liquid chromatography coupled with tandem mass spectrometry (RRLC-MS/MS) method for the simultaneous analysis of seven ginsenosides and three aconitum alkaloids in Shen-Fu decoction, the decoction of Radix ginseng and Fuzi (Radix Aconiti lateralis praeparata). Chromatogrpahic separation by RPLC was achieved using a reversed-phase column and a water/acetonitrile mobile phase, containing $0.05 \%$ formic acid and using a gradient system. The method was optimized to allow for simultaneous analysis of all analytes in 11 minutes without the need for baseline resolution of the components. Furthermore, the separation demonstrated good linearity ( $r>0.9882)$, repeatability (RSD $<7.01 \%$ ), intra- and inter-day precisions (RSD < 5.06\%) and high yields of recovery (91.13-111.97\%) for ten major constituents, namely ginsenoside-Re, $\mathrm{Rg}_{1}, \mathrm{Rb}_{1}, \mathrm{Rc}, \mathrm{Rb} \mathrm{b}_{2}, \mathrm{Rd}, \mathrm{Rf}$, aconitine, hypacoitine and mesaconitine.

Conclusions: The developed method could be used as a rapid and reliable approach for assessment of the quantity of the major constituents in Shen-Fu decoction.
\end{abstract}

Keywords: Ginsenosides, Aconitum alkaloids, Shen-Fu decoction, RRLC-MS/MS

\section{Background}

Decoction is the traditional prescription of traditional Chinese medicines (TCMs). Based on TCM theory, one single herb or several kinds of herbs combined are boiled in water to make the decoction. First documented in 1465, Shen-Fu decoction is a TCM prescription with a 3:2 ratio of Radix Ginseng and Fuzi (Radix Aconiti lateralis praeparata). Both components have been commonly used as herbal medicines in China for about 1800 years, predominantly used for folk treatment of diseases with the sign of Yangqi decline or Yang exhaustion.

\footnotetext{
* Correspondence: maguizhi000@sina.com; deqiangdou@126.com ${ }^{4}$ College of Pharmacy, Xinjiang Medical University, Urumqi 830011, China ${ }^{6}$ Department of Chinese Medicine Chemistry, Liaoning University of Traditional Chinese Medicine, Dalian 116600, China

Full list of author information is available at the end of the article
}

Shen-Fu decoction is also used to treat cardiovascular diseases such as circulatory collapse, shock, thoracic obstruction and acute thoracic pain. Shen-Fu Injection (SFI for intravenous medication), is a typical form of Shen-Fu decoction, that has been used for treatment of many kinds of diseases because of its cardiovascular protective effectiveness [1-3]. The main active components found in Shen-Fu decoction are ginsenosides and alkaloids. Ginsenosides are generally classified into four groups: protopanaxadiol, protopanaxatriol, ocotillol and oleanolic acid type [4-6], Currently, more than 150 ginsenosides have been isolated and identified in the literature. Among them, ginsenosides- $\mathrm{Rb}_{1}, \mathrm{Rb}_{2}, \mathrm{Rc}, \mathrm{Rd}, \mathrm{Rg}_{1}$, Re and Rf (Figure 1) are the most important compounds in chemical analysis of ginsengs. At present, about 224 alkaloids have been isolated and identified from Aconitum [7,8].
() Chemistry Central

(c) 2013 Guo et al.; licensee Chemistry Central Ltd. This is an open access article distributed under the terms of the Creative Commons Attribution License (http://creativecommons.org/licenses/by/2.0), which permits unrestricted use, distribution, and reproduction in any medium, provided the original work is properly cited. 


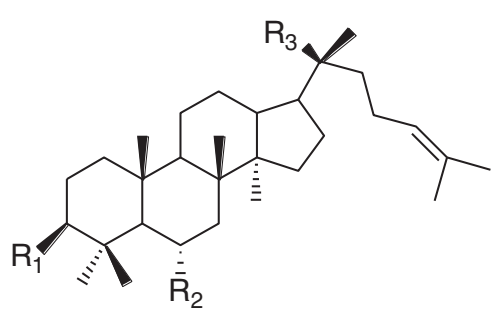

\begin{tabular}{|c|c|c|c|}
\hline Compound & $\mathrm{R}_{1}$ & $\mathrm{R}_{2}$ & $\mathrm{R}_{3}$ \\
\hline $\begin{array}{l}\text { Protopanaxadiol-type } \\
\text { Ginsenoside-Rb1 } \\
\text { Ginsenoside-Rb2 } \\
\text { Ginsenoside-Rc } \\
\text { Ginsenoside-Rd }\end{array}$ & $\begin{array}{l}-O-G|c 2-1 G| c \\
-O-G|c 2-1 G| c \\
-O-G|c 2-1 G| c \\
-O-G|c 2-1 G| c\end{array}$ & $\begin{array}{l}-\mathrm{H} \\
-\mathrm{H} \\
-\mathrm{H} \\
-\mathrm{H}\end{array}$ & $\begin{array}{l}\text {-O-Glc6-1Glc } \\
\text {-O-Glc6-1Arap } \\
\text {-O-Glc6-1Araf } \\
\text {-O-Glc }\end{array}$ \\
\hline $\begin{array}{l}\text { Protopanaxadiol-type } \\
\text { Ginsenoside-Re } \\
\text { Ginsenoside-Rg1 } \\
\text { Ginsenoside-Rf }\end{array}$ & $\begin{array}{l}-\mathrm{OH} \\
-\mathrm{OH} \\
-\mathrm{OH}\end{array}$ & $\begin{array}{l}\text {-O-Glc2-1Rha } \\
-O-G \mid c \\
-O-G l c 2-1 G \mid c\end{array}$ & $\begin{array}{l}\text {-O-Glc } \\
-\mathrm{O}-\mathrm{Glc} \\
-\mathrm{OH}\end{array}$ \\
\hline
\end{tabular}

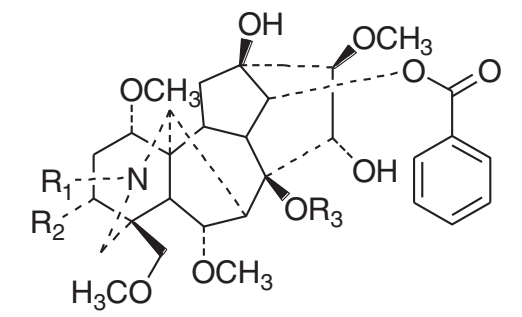

$\begin{array}{cccc}\text { Compound } & \mathrm{R}_{1} & \mathrm{R}_{2} & \mathrm{R}_{3} \\ \mathrm{AC} & \mathrm{C}_{2} \mathrm{H}_{5} & \mathrm{OH} & \text { acetyl } \\ \mathrm{MA} & \mathrm{CH}_{3} & \mathrm{OH} & \text { acetyl } \\ \mathrm{HA} & \mathrm{CH}_{3} & \mathrm{H} & \text { acetyl }\end{array}$

Figure 1 Chemical structures of ginsenosides and Aconitum alkaloids analyzed in Shen-Fu decoction.

These have been classified into four major groups, nonester alkaloids (NEAs), monoester diterpene alkaloids (MDAs), diester diterpene alkaloids (DDAs) and lipoalkaloids. Aconitum alkaloids are mainly constituted of three DDAs, diester-diterpence called aconitine (AC), measaconitine (MA) and hypaconitine (HA) (Figure 1). They are known for their high toxicity and pharmacological activity, as well as being the target markers of Fuzi. In general, the curative effect of traditional Chinese medicine is an integrative result of a number of ginsenosides and alkaloids. In order to minimize the variability of active ingredients in the decoction and ensure repeatable and reproducible therapeutic effects, it is very important to establish quality control methodology for the decoction. To this end, analysis of ginsenosides and Aconitum alkaloids is required to assess the quality of Shen-Fu decoction.

Previous methods that have been used to analyze ginsenosides and alkaloids include HPLC-DAD (ELSD),
CE, GC-MS and LC-MS [9-19] and alkaloids [20-30]. In comparison with traditional HPLC, RRLC provides a higher peak capacity, greater resolution, increased sensitivity and higher speed of analysis. When coupled to a triple quadrupole tandem mass spectrometer (QQQ-MS/ MS), it can achieve high sensitivity and selectivity by using the multiple reaction monitoring (MRM) scan mode without the baseline chromatographic separation of target analytes. This method greatly facilitates the quantification of chemical markers in complex matrixes with only a small amount of sample. To date, there are no studies reporting the simultaneously quantitative determination of ginsenosides and Aconitum alkaloids in Shen-Fu decoction. The primary aim of the present study was to develop a direct and rapid RRLC-MS/MS method for simultaneously quantifying the ten constituents in Shen-Fu decoction, namely, ginsenosides-Rb1, Rb2, Rc, Rd, Rg1, Re and Rf and Aconitum alkaloids including AC, MA and HA. 


\section{Results and discussion}

\section{Chromatographic conditions and MS/MS method development}

Different mobile phases, including acetonitrile with $0.05 \%$, $0.1 \%$ aqueous formic acid, acetic acid, $5 \mathrm{mM}$ and $10 \mathrm{mM}$ ammonium formate solutions were tested. The best peak shape and resolution was obtained with a mixture of acetonitrile and aqueous $0.05 \%$ formic acid solution. Using an optimized elution gradient, the main components were separately eluted within $11 \mathrm{~min}$. The typical RRLC-QQQ MS/MS chromatograms of the marker chemicals in Shen-Fu decoction are shown in Figure 2. In order to increase sensitivity and specificity of quantification, multiple reaction monitoring was performed. All factors related with MS performance including ionization mode, capillary voltage, fragmentor voltage, collision energy, gas flow and desolvation temperature were analyzed. The optimum conditions were determined as follows: postive ion mode, capillary voltage $4000 \mathrm{~V}$, drying gas, gas temperature $350^{\circ} \mathrm{C}$ and nebulizer pressure of 50 psi.

Optimization of this MS/MS method produced highest achiveable response using the MRM pairs comprising of the precursor and product ions, which can achieve better quantitation than reported results using the selected ion monitoring (SIM) mode. After optimization, the precursor and product ions of the ten analytes were recorded (Table 1). The optimum collision energy was determined to be $50 \mathrm{eV}$ for Ginsenoside Re, $40 \mathrm{eV}$ for $\mathrm{Rg}_{1}, 55 \mathrm{eV}$ for $\mathrm{Rf}$ and $\mathrm{Rd}, 65 \mathrm{eV}$ for $\mathrm{Rb}_{1}, \mathrm{Rc}$ and $\mathrm{Rb}_{2}$. For alkaloids, they required a lower collision energy of $35 \mathrm{eV}$ for MA, $40 \mathrm{eV}$ for $\mathrm{HA}$ and $45 \mathrm{eV}$ for AC (Table 1).

\section{Method validation}

To determine the reliability of the test results, the method validation included linearity, repeatability, intra- and interday precisions and recovery test. The standard calibration curves of all compounds were shown in Table 2 with satisfactory linearity $(\mathrm{r}>0.9882)$. Aconitum alkaloids had a linear range of $0.03 \mathrm{ng} \mathrm{mL} L^{-1}$ to $6.24 \mathrm{ng} \mathrm{mL}^{-1}$, whereas ginsenosides displayed a wider linear range of $3.90 \mathrm{ng} \mathrm{mL}^{-1}$ to $125.00 \mathrm{ng} \mathrm{mL}^{-1}$ (Table 2). The limit of dectection (LOD) ranged from $0.01 \mathrm{ng} \mathrm{mL} \mathrm{m}^{-1}$ to $1.25 \mathrm{ng} \mathrm{mL}^{-1}$ for all ten analytes. The intra-day and inter-day with RSD less than $5.06 \%$ are demonstrated in Table 2 . The repeatability was satisfactory with RSD below $7.01 \%$. Recovery of the ten compounds (Table 3) was within the range of 91.13$111.97 \%$ and showed no relevant difference in the percent
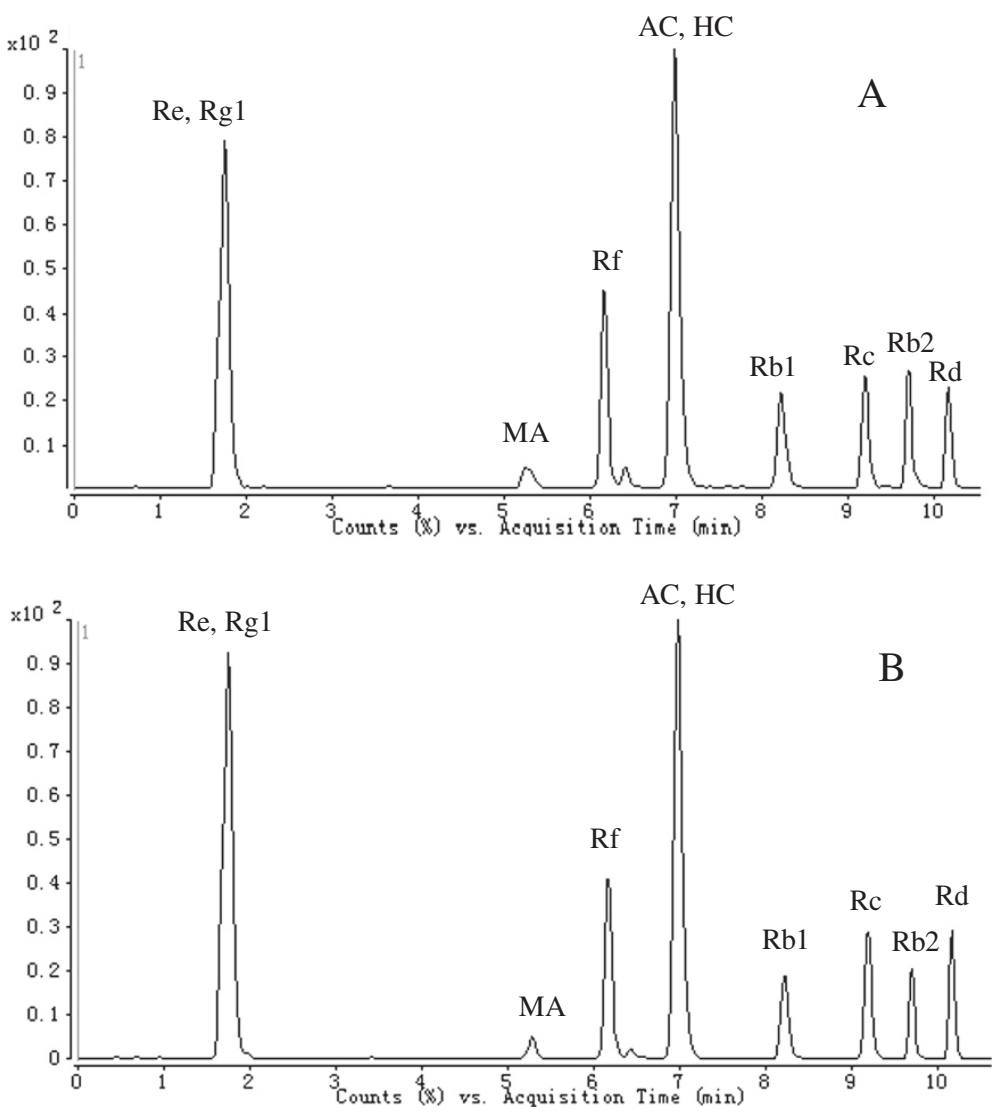

Figure 2 Typical RRLC-QQQ MS/MS chromatograms of marker chemicals in Shen-Fu decoction (A) standard mixture (B) Shen-Fu decoction. 
Table 1 Mass spectra properties of ten compounds in Shen-Fu decoction

\begin{tabular}{ccccc}
\hline Compound name & Precursor ion & Product ion & Frag (V) & CE (V) \\
\hline Ginsenoside Re & 969.6 & 789.5 & 150 & 50 \\
Ginsenoside $\mathrm{Rg}_{1}$ & 823.5 & 643.5 & 135 & 40 \\
Ginsenoside $\mathrm{Rf}$ & 823.3 & 365.3 & 140 & 55 \\
Ginsenoside $\mathrm{Rb}_{1}$ & 1131.6 & 365.0 & 150 & 65 \\
Ginsenoside $\mathrm{Rc}$ & 1101.7 & 335.0 & 150 & 65 \\
Ginsenoside $\mathrm{Rb}_{2}$ & 1101.6 & 334.8 & 150 & 65 \\
Ginsenoside $\mathrm{Rd}$ & 969.9 & 789.3 & 150 & 55 \\
Aconitine & 646.4 & 586.4 & 135 & 45 \\
Mesaconitine & 632.3 & 572.3 & 135 & 35 \\
Hypacoitine & 616.3 & 556.2 & 135 & 40 \\
\hline
\end{tabular}

yield recovered using with different concentrations of the compounds. Thus, the ten analytes can be quantitatively analyzed simultaneously in a relatively short-time using this optimized method.

\section{Sample analysis}

The described RRLC-QQQ-MS/MS method was subsequently applied to the analysis of Shen-Fu decoction, made by authenticated Radix ginseng and aconite root (see method part). The quantitative analytical results are shown in Table 4. The repeatability of the ten analytes in the Shen-Fu decoction was reliable ( $\mathrm{RSD}<6.28 \%$ ). From Table 4, Shen-Fu decoction showed higher amounts of ginsenosides than alkaloids. This result meant that the Shen-Fu decoction may have very low toxicity levels, as aconitine, hypacoitine and mesaconitine are the main toxicity source of some toxic herbal medicines [27]. Furthermore, ginsenoside-Rb1 was the most abundant of the ten compounds in Shen-Fu decoction. Conversely, aconitine was shown to be the least abundant of the ten compounds in Shen-Fu decoction. This method would allow for comparison of the quantity of ginsenosides and alkaloids between Shen-Fu decoction preparations and could therefore be used as a rapid and reliable approach for assessment of the quality of Shen-Fu decoction.

\section{Materials and methods}

\section{Chemicals, standards and samples}

HPLC grade acetonitrile was purchased from Merck (Germany) and MS grade formic acid from Sigma-Aldrich. All other chemicals and solvents were of an analytical grade. Ultrapure water $(18.2 \mathrm{M} \Omega)$ was prepared with a Milli-Q water purification system (Millipore, Bedford, MA, USA).

The standards reference samples of Ginsenosides $R b_{1}$, $\mathrm{Rb}_{2}$, Rc, $\mathrm{Rd}, \mathrm{Rg}_{1}$, Re, Rf, AC, HA and MA were purchased from the National Institute for Control of Pharmaceutical and Biological Products (Beijing, China). The purity of the standards was relatively high at no less than $98 \%$. Radix ginseng was purchased from Liaoning luyuan Pharmaceutical Co., Ltd. in China. The processed aconite root was purchased from Tong-Ren-Tang Pharmaceutical store (Beijing, PR China). Panax ginseng and the prepared aconite root were authenticated by Professor Xirong, He, Insitute of traditional Chinese medicine, China Academy of Chinese Medical Sciences.

\section{Sample preparation \\ Reference standards solutions}

Stock solutions were prepared by accurate measurement of ginsenoside $R e, \mathrm{Rg}_{1}, \mathrm{Rf}, \mathrm{Rb}_{1}, \mathrm{Rc}, \mathrm{Rb}_{2}, \mathrm{Rd}$, aconitine, hypacoitine and mesaconitine. They were dissolved with methanol respectively to get ten reference standards stock solutions $\left(1.0 \mathrm{mg} \mathrm{mL}^{-1}\right)$, and were stored at $4{ }^{\circ} \mathrm{C}$.

\section{Extracts of shen-fu decoction}

ShenFu Formula (SF) was prepared by combining of Radix ginseng and the processed aconite root (at a ratio of 3:2). Dried and pulverized white ginseng (18 g) and

Table 2 Calibration curves, LOD, LOQ, Precision and Repeatability for ten compounds in Shen-Fu decoction

\begin{tabular}{|c|c|c|c|c|c|c|c|c|}
\hline Compound name & Calibration curve & $r$ & $\begin{array}{c}\text { Linear range } \\
\left(\mathrm{ng} \cdot \mathrm{mL}^{-1}\right)\end{array}$ & $\begin{array}{c}\text { LOD } \\
\left(\mathrm{ng} \cdot \mathrm{mL}^{-1}\right)\end{array}$ & $\begin{array}{c}\mathrm{LOQ} \\
\left(\mathrm{ng} \cdot \mathrm{mL}^{-1}\right)\end{array}$ & $\begin{array}{c}\text { Intra-day } \\
(n=6)\end{array}$ & $\begin{array}{c}\text { Inter-day } \\
(n=6)\end{array}$ & $\begin{array}{c}\text { Repeatability } \\
(n=5)\end{array}$ \\
\hline Ginsenoside- $\mathrm{Rb}_{1}$ & $Y=11.04 X+181.44$ & 0.9930 & $3.90 \sim 125.00$ & 0.97 & 3.00 & 3.44 & 4.11 & 6.51 \\
\hline Ginsenoside- $\mathrm{Rb}_{2}$ & $Y=31.68 X+246.74$ & 0.9882 & $3.90 \sim 125.00$ & 0.97 & 3.00 & 2.23 & 3.55 & 7.01 \\
\hline Ginsenoside-Rc & $Y=20.13 X+25.79$ & 0.9921 & $3.90 \sim 125.00$ & 1.25 & 3.00 & 2.02 & 3.92 & 4.21 \\
\hline Ginsenoside-Rd & $Y=13.60 X+69.00$ & 0.9993 & $3.90 \sim 125.00$ & 0.75 & 1.95 & 4.18 & 4.71 & 3.16 \\
\hline Ginsenoside-Re & $Y=18.52 X+136.68$ & 0.9973 & $3.90 \sim 125.00$ & 0.48 & 1.95 & 3.34 & 5.06 & 4.67 \\
\hline Ginsenoside-Rf & $Y=37.66 X+473.14$ & 0.9952 & $3.90 \sim 125.00$ & 0.97 & 3.00 & 2.05 & 3.12 & 5.03 \\
\hline Ginsenoside- $\mathrm{Rg}_{1}$ & $Y=52.38 X+109.20$ & 0.9994 & $3.90 \sim 125.00$ & 0.48 & 1.50 & 2.29 & 2.49 & 4.12 \\
\hline Aconitine & $Y=6193.52 X-80.34$ & 0.9996 & $0.03 \sim 1.25$ & 0.01 & 0.04 & 2.76 & 3.51 & 4.45 \\
\hline Mesaconitine & $Y=3617.22 X-63.02$ & 0.9939 & $0.03 \sim 1.25$ & 0.01 & 0.04 & 3.97 & 3.28 & 4.96 \\
\hline Hypaconitine & $Y=1207.82 X+180.44$ & 0.9960 & $0.19 \sim 6.24$ & 0.01 & 0.04 & 2.55 & 2.42 & 4.81 \\
\hline
\end{tabular}


Table 3 Analsysis of the recovery of ten compounds in Shen-Fu decoction

\begin{tabular}{|c|c|c|c|c|c|}
\hline Compounds & Initial amount (ng) & Added amount (ng) & Detected amount (ng) & Recovery (\%) & $\mathrm{RSD} / \%(\mathrm{n}=5)$ \\
\hline \multirow[t]{3}{*}{ Ginsenosid-Re } & 2074.12 & 1700 & $3673.54 \pm 230.37$ & 94.08 & 6.27 \\
\hline & 2074.12 & 2100 & $3991.27 \pm 117.73$ & 91.29 & 2.95 \\
\hline & 2074.12 & 2500 & $4475.56 \pm 236.76$ & 96.06 & 5.29 \\
\hline \multirow[t]{3}{*}{ Ginsenoside- $\mathrm{Rg}_{1}$} & 2260.51 & 1800 & $3959.88 \pm 307.37$ & 94.41 & 7.76 \\
\hline & 2260.51 & 2250 & $4310.87 \pm 229.80$ & 91.13 & 5.33 \\
\hline & 2260.51 & 2700 & $5176.34 \pm 166.16$ & 107.99 & 3.21 \\
\hline \multirow[t]{3}{*}{ Ginsenoside- $\mathrm{Rb}_{1}$} & 2423.46 & 2000 & $4299.39 \pm 196.65$ & 93.80 & 4.57 \\
\hline & 2423.46 & 2500 & $4812.75 \pm 185.92$ & 95.57 & 3.86 \\
\hline & 2423.46 & 3000 & $5271.72 \pm 130.37$ & 94.94 & 2.47 \\
\hline \multirow[t]{3}{*}{ Ginsenoside-Rc } & 2231.62 & 1800 & $3933.62 \pm 155.38$ & 94.56 & 3.95 \\
\hline & 2231.62 & 2250 & $4644.8 \pm 231.31$ & 107.25 & 4.98 \\
\hline & 2231.62 & 2700 & $5043.67 \pm 244.21$ & 104.15 & 4.84 \\
\hline \multirow[t]{3}{*}{ Ginsenoside- $\mathrm{Rb}_{2}$} & 1597.95 & 1200 & $2880.31 \pm 83.82$ & 106.86 & 2.91 \\
\hline & 1597.95 & 1500 & $3277.51 \pm 128.48$ & 111.97 & 3.92 \\
\hline & 1597.95 & 1800 & $3510.26 \pm 169.97$ & 106.24 & 4.84 \\
\hline \multirow[t]{3}{*}{ Ginsenoside-Rd } & 816.73 & 640 & $1416.19 \pm 86.39$ & 93.67 & 6.10 \\
\hline & 816.73 & 800 & $1642.99 \pm 95.82$ & 103.28 & 5.83 \\
\hline & 816.73 & 960 & $1700.19 \pm 80.93$ & 92.03 & 4.76 \\
\hline \multirow[t]{3}{*}{ Ginsenoside-Rf } & 2000.12 & 1600 & $3563.83 \pm 252.68$ & 97.73 & 7.09 \\
\hline & 2000.12 & 2000 & $4173.63 \pm 261.27$ & 108.68 & 6.26 \\
\hline & 2000.12 & 2400 & $4549.1 \pm 256.57$ & 106.21 & 5.64 \\
\hline \multirow[t]{3}{*}{ Aconitine } & 2.91 & 2.4 & $5.52 \pm 0.27$ & 108.75 & 4.89 \\
\hline & 2.91 & 3.0 & $5.67 \pm 0.31$ & 92.00 & 5.47 \\
\hline & 2.91 & 3.6 & $6.7 \pm 0.34$ & 105.28 & 5.07 \\
\hline \multirow[t]{3}{*}{ Mesaconitine } & 7.12 & 5.6 & $12.98 \pm 0.66$ & 104.64 & 5.08 \\
\hline & 7.12 & 7.0 & $13.74 \pm 0.68$ & 94.57 & 4.95 \\
\hline & 7.12 & 8.4 & $15.82 \pm 0.56$ & 103.57 & 3.54 \\
\hline \multirow[t]{3}{*}{ Hypaconitine } & 100.06 & 80 & $174.69 \pm 7.95$ & 93.29 & 4.55 \\
\hline & 100.06 & 100 & $204.9 \pm 10.90$ & 104.84 & 5.32 \\
\hline & 100.06 & 120 & $225.07 \pm 7.81$ & 104.18 & 3.47 \\
\hline
\end{tabular}

the processed aconite root (12 g) were ground and then refluxed three times with $300 \mathrm{~mL}$ of water for $60 \mathrm{~min}$ at $100^{\circ} \mathrm{C}$. After cooling, the extracted solutions were filtered under vacuum. The solutions were condensed under decompression and finally were freeze-dried. The decoction extract was dissolved in a measured volume of water with a concentration equal to $10 \mathrm{mg}$ of crude botanicals per milliliter. $1 \mathrm{~mL}$ of the solution was precipitated with $8 \mathrm{~mL}$ ethanol allowed to sit for $24 \mathrm{~h}$ at $4^{\circ} \mathrm{C}$. The solution was filtered under vacuum. The filtrate was transferred to a $50 \mathrm{~mL}$ volumetric flask. Prior to injection, all samples were filtered through a $0.22 \mu \mathrm{m}$ membrane filter.

\section{RRLC-MS conditions}

An Agilent-1200 RRLC/6410A QQQ system (Agilent, MA, USA) equipped with an electrospray ionization (ESI) source and operated in positive ion mode (data analysis software Masshunter version B.01.04) was used for the simultaneous determination of seven ginsenosides and

Table 4 Contents of ten compounds in Shen-Fu decoction

\begin{tabular}{|c|c|c|c|c|c|c|c|c|c|c|}
\hline \multirow[t]{2}{*}{ Samples } & \multicolumn{10}{|c|}{ Content $(\mu \mathrm{g} / \mathrm{g})$} \\
\hline & $\mathrm{Rb}_{1}$ & Rd & $\operatorname{Re}$ & $\mathrm{Rf}$ & $\mathrm{Rg}_{1}$ & $\mathrm{Rc}$ & $\mathrm{Rb}_{2}$ & Aconitine & Mesaconitine & Hypaconitine \\
\hline & $247.17 \pm 11.27$ & $84.21 \pm 4.31$ & $210.64 \pm 12.66$ & $204.66 \pm 10.24$ & $231.22 \pm 11.75$ & $223.19 \pm 14.01$ & $121.16 \pm 7.41$ & $0.21 \pm 0.01$ & $0.76 \pm 0.04$ & $10.05 \pm 0.48$ \\
\hline
\end{tabular}


three aconitum alkaloids in Shen-Fu decoction. The separation was performed on an Agilent ZORBAX C18 SB column $(100 \mathrm{~mm} \times 2.1 \mathrm{~mm}, 1.8 \mu \mathrm{m})$. The gradient mobile phases consisted of (A) water containing $0.05 \%$ formic acid and (B) acetonitrile for gradient elution from the column at $40^{\circ} \mathrm{C}$. The linear gradient conditions assessed for gradient optimization were as follows: $0-2 \mathrm{~min}, 28-34 \% \mathrm{~B}$; 2-6 min, 34-35\%; 6-10 min, 35-100\%; 10-11 min, 100\%. The flow rate was $0.35 \mathrm{ml} / \mathrm{min}$. The column temperature was $40^{\circ} \mathrm{C}$. The conditions for MS analysis were as follows: drying gas $\mathrm{N}_{2}$ flow rate $12 \mathrm{~L} \mathrm{~min}^{-1}$, gas temperature $350^{\circ} \mathrm{C}$ and nebulizer pressure was $50 \mathrm{psi}$. The capillary voltage was set to $4000 \mathrm{~V}$. MRM was employed for quantification. The precursor-to-product ion pair, fragmentor voltage (Frag V) and collision energy (CE) for each analyte are described (Table 1). The dwell time of each ion pair was $200 \mathrm{~ms}$.

\section{Method validation}

An external calibration method was used for quantitative analysis with the linear calibration curves constructed using six different concentrations of the ten compounds. Each concentration was analyzed in triplicate and then the calibration curves were constructed by plotting the peak areas versus the concentrations of each analyte. The LOD and limit of quantification (LOQ) were measured with the signal-to-noise ratios of $3: 1$ and 10:1, respectively. The intra-day precision was determined by analysis of the standard solution at six times within 1 day. Inter-day precision on other hand, was determined by repeated analysis of the sample for three consecutive days. For the assessment of experimental repeatability test, five independent sample solutions were prepared by the procedures noted in Extracts of Shen-Fu decoction. The recovery of this method was determined using the standard addition method. Three different concentration levels (approximately equivalent to $0.8,1.0$ and 1.2 times of the concentration of the original amount in the matrix) of the references standards were added into the sample in triplicate. The average recoveries were determined by the following equation: $\operatorname{Recovery}(\%)=$ (Observed amount-Original amount)/Spiked amount $x$ $100 \%$, RSD $(\%)=(\mathrm{SD} /$ mean $) \times 100 \%$.

\section{Conclusions}

This is the first report of the simultaneous determination of the major compounds in Shen-Fu decoction. By using RRLC coupled with an ESI triple quadrupole tandem spectrometer, we developed and validated a rapid, simple and reliable method to simultaneously determine ten marker chemicals (ginsenoside $R e, \mathrm{Rg}_{1}, \mathrm{Rb}_{1}, \mathrm{Rc}, \mathrm{Rb}_{2}$, $\mathrm{Rd}$, Rf, aconitine, hypacoitine and mesaconitine) in the Shen-Fu decoction. This method provides an excellent quantitative tool for the quality assessments of TCM formulae because of its high capacity, high sensitivity, high selectivity and short analysis time.

\section{Abbreviations}

RRLC-MS/MS: Rapid resolution liquid chromatography coupled with tandem mass spectrometry; QQQ-MS/MS: Triple quadrupole tandem mass spectrometer; RSD: Relative standard deviations; TCMs: Traditional Chinese medicines; SFI: Shen-Fu Injection; SIM: Selected ion monitor; MRM: Multiple reaction monitor; ESI: Electrospray ionization; Frag V: Fragmentor voltage; CE: Collision energy; LOD: Limit of detection; LOQ: Limit of quantification; NEAs: Nonester alkaloids; MDAs: Monoester diterpene alkaloids; DDAs: Diester diterpene alkaloids; AC: Aconitine; MA: Measaconitine; HA: Hypaconitine.

\section{Competing interests}

The authors declare that they have no competing interests.

\section{Authors' contributions}

GN, M-GZ and D-DQ conceived of the study, participated in its design and coordination, and drafted the manuscript. GN, L-MT and Y-DW performed experiments and analyzed results and helped to draft the manuscript. $\mathrm{HY}, \mathrm{N}-\mathrm{XH}, \mathrm{W}-\mathrm{RF}$ and $\mathrm{LY}$ helped to do experiments. All authors read and approved the manuscript.

\section{Acknowledgments}

This work was financially supported by 2013 Program for Liaoning Innovative Research Team in University (LT2013020 the Autonomic Project of China Academy of Chinese Medicine Sciences (project number zz2012011) and the National Natural Science Foundation of China (Grant 81001597 and 81370095).

\section{Author details}

${ }^{1}$ Experimental Research Center, China Academy of Chinese Medical Sciences, Beijing 100700, China. ${ }^{2}$ SRI International, Menlo Park, CA 94025, USA. ${ }^{3}$ Key Laboratory of Biofuels, Qingdao Institute of Bioenergy and Bioprocess Technology, Chinese Academy of Sciences, Songling road 189, Qingdao 266101, China. ${ }^{4}$ College of Pharmacy, Xinjiang Medical University, Urumai 830011, China. ${ }^{5}$ Key Laboratory of Bioactive Substances and Resource Utilization of Chinese Herbal Medicine, Ministry of Education, Institute of Materia Medica, Chinese Academy of Medical Sciences and Peking Union Medical College, Beijing 100050, China. ${ }^{6}$ Department of Chinese Medicine Chemistry, Liaoning University of Traditional Chinese Medicine, Dalian 116600, China.

Received: 9 July 2013 Accepted: 9 September 2013 Published: 10 October 2013

\section{References}

1. Wang YL, Wang CY, Zhang BJ, Zhang ZZ: Shenfu injection suppresses apoptosis by regulation of $\mathrm{BCl}-2$ and caspase-3 during hypoxia/ reoxygenation in neonatal rat cardiomyocytes in vitro. Mol Biol Rep 2009, 36:365-370

2. Zheng $C D$, Min S: Cardioprotection of Shenfu Injection against myocardial ischemia/reperfusion injury in open heart surgery. Chin J Integr Med 2008, 14:10-16.

3. Luo J, Min S, Wei K, Cao J: Ion channel mechanism and ingredient bases of Shenfu Decoction's cardiac electrophysiological effects. J Ethnopharmacol 2008, 117:439-445.

4. Chu S, Zhang J: New achievements in ginseng research and its future prospects. Chin J Integr Med 2009, 15:403-408.

5. Jia L, Zhao Y: Current evaluation of the millennium phytomedicineginseng (I): etymology, pharmacognosy, phytochemistry, market and regulations. Curr Med Chem 2009, 16:2475-2484.

6. Jia L, Zhao Y, Liang XJ: Current evaluation of the millennium phytomedicine-ginseng (II): collected chemical entities, modern pharmacology, and clinical applications emanated from traditional Chinese medicine. Curr Med Chem 2009, 16:2924-2942.

7. Judith S, Ming Z, Sonja P, Brigitte K: Aconitum in traditional Chinese medicine-a valuable drug or an unpredictable risk. j. J Ethnopharmacol 2009, 126:18-30

8. Gao F, Li YY, Wang D, Huang X, Liu Q: Diterpenoid Alkaloids from the Chinese Traditional Herbal "Fuzi" and Their Cytotoxic Activity. Molecules 2012, 17:5187-5194.

9. Liu Y, Yang J, Cai Z: Chemical investigation on Sijunzi decoction and its two major herbs Panax ginseng and Glycyrrhiza uralensis by LC/MS/MS. J Pharm Biomed Anal 2006, 41:1642-1647. 
10. Qi LW, Wang CZ, Yuan CS: Isolation and analysis of ginseng: advances and challenges. Nat Prod Rep 2011, 28:467-495.

11. Xie GX, Plumb R, Su MM, Xu ZH, Zhao AH, Qiu MF, Long XB, Liu Z, Jia W: Ultra-performance LC/TOF MS analysis of medicinal Panax herbs for metabolomic research. J Sep Sci 2008, 31:1015-1026.

12. Toh DF, New LS, Koh HL, Chan ECY: Ultra-high performance liquid chromatography/time-of-flight mass spectrometry (UHPLC/TOFMS) for time-dependent profiling of raw and steamed Panax notoginseng. J Pharm Biomed Anal 2010, 52:43-50.

13. Hu P, Luo GA, Wang Q, Zhao ZZ, Wang W, Jiang ZH: The Retention Behavior of Ginsenosides in HPLC and Its Application to Quality Assessment of Radix Ginseng. Acta Pharmacol Sin 2009, 32:667-676.

14. Popovich DG, Hu C, Durance TD, Kitts DD: Retention of ginsenosides in dried ginseng root: Comparison of drying methods. J Food Sci 2005, 70:5355-s358.

15. Fuzzati N: Analysis methods of ginsenosides. J Chromatogr B 2004, 812:119-133.

16. Li L, Luo GA, Liang QL, Hu P, Wang YM: Rapid qualitative and quantitative analyses of Asian ginseng in adulterated American ginseng preparations by UPLC/Q-TOF-MS. J Pharm Biomed Anal 2010, 52:66-72.

17. Lai CM, Li SP, Yu H, Wan JB, Kan KW, Wang YT: A rapid HPLC-ESI-MS/MS for qualitative and quantitative analysis of saponins in "XUESETONG" injection. J Pharm Biomed Anal 2006, 40:669-678.

18. Qi LW, Wang HY, Zhang H, Wang CZ, Li P, Yuan CS: Diagnostic ion filtering to characterize ginseng saponins by rapid liquid chromatography with time-of-flight mass spectrometry. J Chromatogr A 2012, 1230:93-99.

19. Yu Q, Yu B, Yang H, Li X, Liu S: Silver (I)-assisted enantiomeric analysis of ginsenosides using electrospray ionization tandem mass spectrometry. J Mass Spectrom 2012, 47:1313-1321.

20. Wang JS, van der Heijden R, Spijksma G, Reijmers T, Wang M, Xu GW, et al: Alkaloid profiling of the Chinese herbal medicine Fuzi by combination of matrix-assisted laser desorption ionization mass spectrometry with liquid chromatography-mass spectrometry. J Chromatogr A 2009, 1216:2169-2178.

21. Tang L, Gong Y, Lv C, Ye L, Liu L, Liu Z: Pharmacokinetics of aconitine as the targeted marker of Fuzi (Aconitum carmichaeli) following single and multiple oral administrations of Fuzi extracts in rat by UPLC/MS/MS J Ethnopharmacol 2012, 141:736-741.

22. Chen JH, Lee CY, Liau BC, Lee MR, Jong TT, Chiang ST: Determination of aconitine-type alkaloids as markers in fuzi (Aconitum carmichaeli) by LC/(+) ESI/MS3. J Pharm Biomed Anal 2009, 48:1105-1111.

23. Liu H, Su J, Yang X, He YJ, Li HY, Ye J, Zhang WD: A novel approach to characterize chemical consistency of traditional Chinese medicine Fuzi Lizhong pills by GC-MS and RRLC-Q-TOFMS. Chin Nat Med 2011, 9:267-273.

24. Wang $X J$, Wang $H Y$, Zhang AH, Lu $X$, Sun $H$, Dong $H$, Wang $P$. Metabolomics study on the toxicity of aconite root and its processed products using ultraperformance liquid-chromatography/electrosprayionization synapt high-definition mass spectrometry coupled with pattern recognition approach and ingenuity pathways analysis. J Proteome Res 2011, 11:1284-1301.

25. Wang $Z \mathrm{ZH}$, Wen J, Xing JB, He Y: Quantitative determination of diterpenoid alkaloids in four species of Aconitum by HPLC. J Pharm Biomed Anal 2006, 40:1031-1034

26. Yan GL, Sun H, Sun WJ, Zhao L, Meng XC, Wang XJ: Rapid and global detection and characterization of aconitum alkaloids in Yin Chen $\mathrm{Si} \mathrm{Ni}$ Tang, a traditional Chinese medical formula, by ultra performance liquid chromatography-high resolution mass spectrometry and automated data analysis. J Pharm Biomed Anal 2010, 53:421-431.

27. Lu GH, Dong ZQ, Wang Q, Qian GS, Huang WH, Jiang ZH, Leung KS, Zhao ZZ: Toxicity assessment of nine types of decoction pieces from the daughter root of Aconitum carmichaeli (Fuzi) based on the chemical analysis of their diester diterpenoid alkaloids. Planta Med 2010, 76:825-830

28. Wu W, Liang ZT, Zhao ZZ, Cai ZW: Direct analysis of alkaloid profiling in plant tissue by using matrix-assisted laser desorption/ionization mass spectrometry. J Mass Spectrom 2007, 42:58-69.
29. Ito K, Ohyama $Y$, Hishinuma T, Mizugaki M: Determination of Aconitum alkaloids in the tubers of Aconitum japonicum using gas chromatography/selected ion monitoring. Planta Med 1996, 62:57-59.

30. Sun $H$, Ni B, Zhang AH, Wang M, Dong H, Wang XJ: Metabolomics study on Fuzi and its processed products using ultra-performance liquidchromatography/electrospray-ionization synapt high-definition mass spectrometry coupled with pattern recognition analysis. Analyst 2012, 137:170-185.

doi:10.1186/1752-153X-7-165

Cite this article as: Guo et al:: Quantitative LC-MS/MS analysis of seven ginsenosides and three aconitum alkaloids in Shen-Fu decoction.

Chemistry Central Journal 2013 7:165.

Publish with ChemistryCentral and every
scientist can read your work free of charge
"Open access provides opportunities to our
colleagues in other parts of the globe, by allowing
anyone to view the content free of charge."
W. Jeffery Hurst, The Hershey Company.
- available free of charge to the entire scientific community
- peer reviewed and published immediately upon acceptance
- cited in PubMed and archived on PubMed Central
- yours - you keep the copyright
submit your manuscript here:
http://www.chemistrycentral.com/manuscript/

